\title{
Sphenopalatine artery ligation under local anesthesia: A report of two cases and review of the literature
}

This article was published in the following Dove Press journal:

Local and Regional Anesthesia

28 January 2010

Number of times this article has been viewed

\section{Nico Jonas \\ Laura Viani \\ MWalsh}

Otolaryngology, Beaumont Hospital, Dublin, Ireland
Correspondence: Nico Jonas

Department of Otolaryngology,

Great Ormond Street Hospital,

Great Ormond Street,

London WCIN 3JH, UK

Tel +442074059200 ext 5226

Email nicojonas@gmail.com
Abstract: Epistaxis is the commonest emergency in otorhinolaryngology. Over the last decade endoscopic sphenopalatine artery (SPA) ligation has become a popular treatment option for posterior epistaxis and has been shown to be the most effective and cost-efficient definitive treatment for posterior epistaxis. SPA ligation is usually performed under general anesthesia. The majority of epistaxis patients are elderly, frail and have multiple medical conditions. These patients are therefore not always amenable to general anesthesia. In this article we describe two cases where posterior epistaxis was successfully treated with sphenopalatine artery ligation under local anesthesia and should be considered suitable for patients with severe posterior epistaxis who are not fit for a general anesthetic.

Keywords: epistaxis, sphenopalatine artery ligation, local anesthesia

\section{Case report I}

A 44-year-old man was involved in a car accident and sustained a head injury in addition to significant injuries to his face and left eye. He reportedly lost consciousness for five minutes immediately after the accident, although he was fully conscious when the paramedics arrived at the scene of the accident. Shortly after arriving at the hospital he became confused and complained of weakness in his left upper limb.

An urgent head computerized tomography (CT) scan was performed and showed no significant brain injury. However, the scan did reveal a fracture of the left orbital floor together will multiple undisplaced nasal fractures (Figure 1). A diagnosis of a non-dominant hemispheric stroke was made and a magnetic resonance imaging (MRI) and magnetic resonance angiography (MRA) were requested. These scans revealed global ischemia of the right cerebral hemisphere as well as dissection of the right internal carotid artery (Figure 2). Because of the high risk of thrombus formation the patient was started on intravenous heparin. Seven days later he developed severe left sided epistaxis requiring posterior nasal packing. His hemoglobin dropped from 13.5 to $8 \mathrm{~g} / \mathrm{dL}$ and in view of further possible life threatening epistaxis the decision was made to discontinue his heparin. As a result the main concern became that he was again at significant risk of a further stroke and heparin was required to prevent this. So that we could re-start his heparin safely it was decided that he needed definitive treatment of his epistaxis. The decision was therefore made to perform both sphenopalatine artery (SPA) and anterior ethmoidal artery ligation.

After discussion with the anesthetist there was concern that this patient was at significant risk of developing a further cerebrovascular accident (CVA) if he 


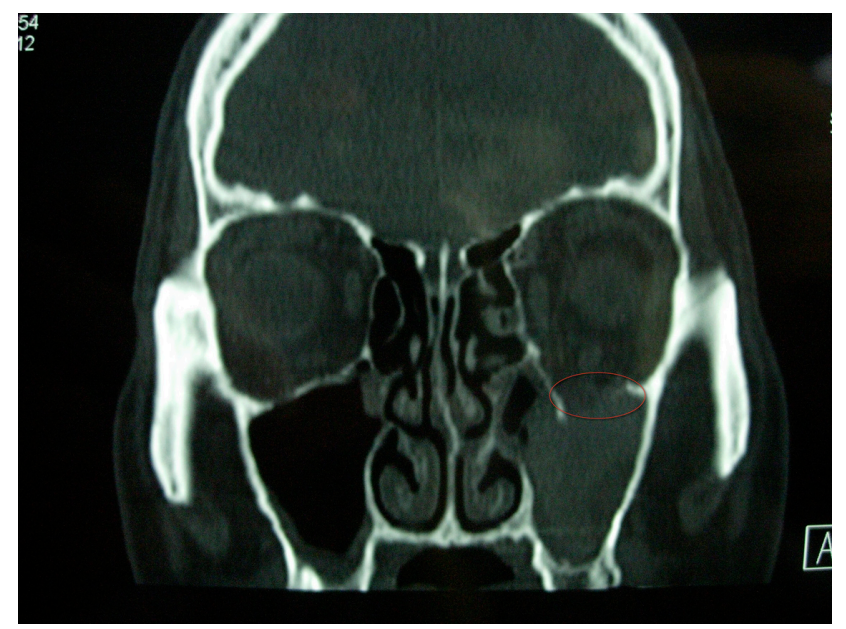

Figure I A computerized tomography (CT) scan of patient I, which reveals a fracture of the left orbital floor (circled) together will multiple undisplaced nasal fractures.

were to undergo a general anesthetic. Embolization was a treatment option for the SPA although not for the anterior ethmoidal artery as this is part of the internal carotid artery system and therefore poses a significant risk of causing a CVA or embolus in the ophthalmic artery with potential visual loss. It was therefore decided that the safest option was to perform the surgery under local anesthesia. The left anterior ethmoidal artery was identified and ligated without any difficulty via the usual medial canthus incision (Lynch incision). The left SPA ligation was performed after preparing the nose with topical anesthetic and decongestant spray, a greater palatine foramen block and local anesthetic infiltration into the lateral wall of the middle meatus.

The greater palatine foramen block was performed in the following way. The foramen was identified by trans-oral palpation of the hard palate in line with the third molar tooth (Figure 3). A 25G needle bent to 45 degrees $2.5 \mathrm{~cm}$ from the tip was used to inject $2 \mathrm{~mL}$ of lidocaine ( $2 \%$ with adrenaline 1:80 000) solution into the foramen. Immediate blanching of the hemi-palate confirmed accurate placement of the needle and subsequent vasoconstriction.

Infiltration of the lateral nasal wall of the middle meatus, with $2 \mathrm{~mL}$ of the same solution mentioned above, was performed under endoscopic guidance. An incision was made in the lateral wall of the medial meatus $1 \mathrm{~cm}$ anterior to the posterior attachment of the middle turbinate. A mucosal flap was raised and the ethmoidal crest and SPA identified as it exits the sphenopalatine foramen. The artery was ligated using metal clips. The mucosal flap was replaced and no nasal packs were inserted after surgery.

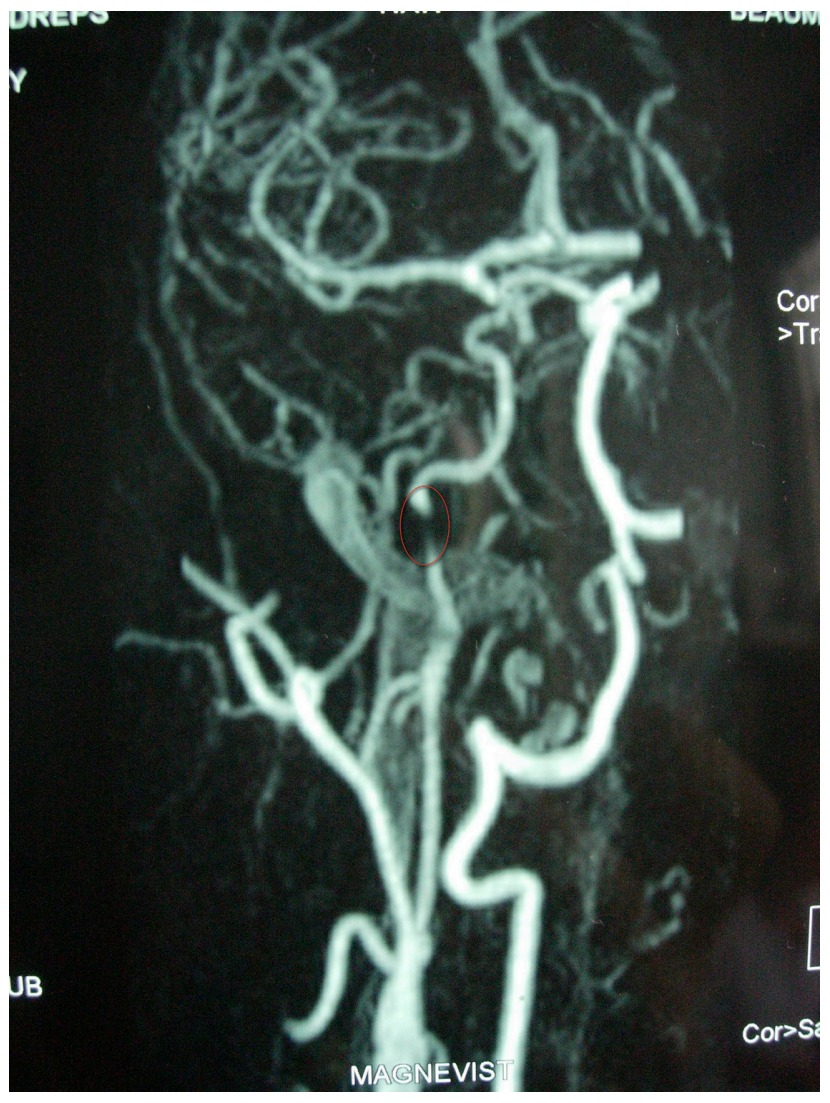

Figure 2 A magnetic resonance angiography (MRA) of patient I, which reveals global ischemia of the right cerebral hemisphere as well as dissection of the right internal carotid artery (circled).

Intravenous (IV) heparin was re-commenced immediately after the procedure. The patient did not have any further bleeding and made good progress with excellent functional recovery of his upper limb. He was subsequently started on warfarin for a further 6 months to prevent further embolic episodes.

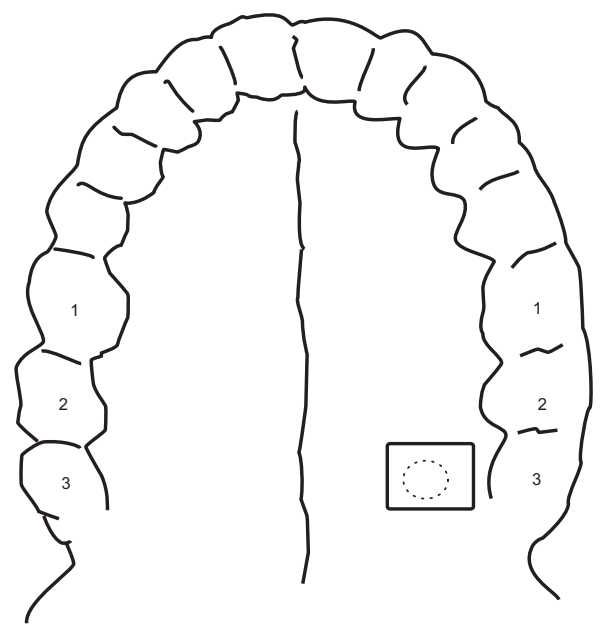

Figure 3 Schematic drawing demonstrating the position of the left greater palatine foramen in line with the third upper molar tooth on the left hand side. 


\section{Case report 2}

A 20-year-old male patient was referred to the otolaryngologist with a history of recurrent right-sided posterior epistaxis. He was a known, oxygen dependant, cystic fibrosis patient awaiting a lung transplant. He required posterior nasal packs on several occasions to control his epistaxis, he found this very troublesome as it prevented him from administering oxygen via a nasal prong and forced him to use a facemask.

After discussion with the patient and the success of the first case it was decided to perform a SPA ligation under local anesthetic to hopefully prevent further epistaxis. The procedure was performed in an identical fashion to the first case. The patient tolerated the procedure very well and again no nasal packs were inserted at the end of the procedure. $\mathrm{He}$ has not had any further bleeding to date -3 months.

\section{Discussion}

Epistaxis is a common condition with an incidence of $108 / 100000$ population, per year. ${ }^{1}$ It is the most common emergency in otorhinolaryngology. The majority of epistaxis will originate from the anterior septum and will be treated with conservative measures.

Posterior epistaxis is usually more severe and often will require posterior nasal packing. Posterior nasal packs including balloon tamponade will fail in $26 \%$ to $52 \%$ of cases, ${ }^{2,3}$ and the next management step will be either surgery or embolization.

Embolization services will only be available at large centers. Traditional surgical options include ligation of one or more of the following arteries: external carotid, internal maxillary and anterior ethmoidal artery. More recently endoscopic SPA ligation has become a popular treatment option for posterior epistaxis. Some authors advocate bilateral SPA ligation with or without anterior ethmoidal artery ligation for the treatment of intractable posterior epistaxis that has failed conventional nasal packing. ${ }^{4}$

Two published studies have reported that surgical intervention was more cost effective than medical treatment or arterial embolization. ${ }^{5,6}$ Endoscopic SPA ligation is the most effective and cost efficient treatment for posterior epistaxis.? In a study involving 127 patients epistaxis was controlled in $98 \%$ of cases. ${ }^{8}$

Microsurgical ligation of the SPA was first described by Prades in the $1970 \mathrm{~s}^{9}$ and endoscopic SPA ligation was first described in 1992 by Budrovich and Saetti. ${ }^{10}$ The majority of large studies report success rates of around $90 \%{ }^{11}$ and a better understanding of the anatomy of the SPA through recent articles should improve the efficacy of the procedure performed. Lee reported that the SPA will divide into 2 to 4 branches before exiting the sphenopalatine foramen. The majority of cases (76\%) will have only two branches. ${ }^{12}$ In $12 \%$ of cases the septal branch of the SPA will emerge from a separate foramen. ${ }^{13}$ This means that the surgeon should actively look for further branches after identifying and ligating the first identifiable branch. Complications are minor and include increased nasal crusting and palatal numbness. ${ }^{14}$

The majority of epistaxis patients are elderly, frail and have multiple medical conditions. ${ }^{15}$ These patients are therefore not always amenable to general anesthesia. Furthermore patients with significant coronary atherosclerosis will not be able to tolerate hypotensive anesthesia in an attempt to reduce bleeding and improve the surgical field. It would therefore be ideal if endoscopic surgery for posterior epistaxis can be performed under local anesthesia and that local bleeding can be controlled without inducing systemic hypotension.

Pterygopalatine fossa infiltration with vasoconstrictors and local anesthesia through the greater palatine foramen has been described in the literature. Surgical access to the pterygopalatine fossa was described as early as 1935 when Averbukh and colleagues described a transpalatine technique to gain access to the sphenopalatine ganglion as well as the second part of the trigeminal nerve for the treatment of trigeminal neuralgia. Furthermore they concluded that the surgery can be performed under local anesthesia. ${ }^{16}$

Vasoconstrictors infiltrated into this space will target the third part of the maxillary artery as it enters the pterygopalatine fossa. This will cause vasospasm of the maxillary artery and decrease blood flow into the sphenopalatine artery with subsequent decrease in blood supply to the nasal cavity mucosa. Infiltration with vasoconstrictor solutions into the greater palatine foramen have been shown to significantly reduce intra-operative bleeding during endoscopic sinus surgery and septorhinoplasty and help control posterior epistaxis. ${ }^{17-19}$

Sensory innervation of the lateral wall of the nasal cavity is supplied by the posterior nasal branches of the maxillary nerve as well as the nasopalatine nerve (itself a branch of the maxillary nerve). The septum is supplied by the nasociliary nerve (a branch of the ophthalmic branch of the trigeminal nerve) and the nasopalatine nerve. Both the nasopalatine nerve and the posterior nasal branches of the maxillary nerve can be reached in the pterygopalatine fossa. This means that the lateral wall of the nasal cavity as well as the posterior aspect of the septum can be successfully 
anesthetized with local anesthetic infiltration of the pterygopalatine fossa via the greater palatine foramen.

Local anesthetic infiltration via this route has been used successfully to provide regional anesthesia for dental procedures as well as improve pain associated with removal of nasal packs following surgery. ${ }^{20,21}$ Cadaver based anatomy studies by Douglas and Wormald suggested that a $25-\mathrm{G}$ needle, bent at 45 degrees, $25 \mathrm{~mm}$ from the tip will ensure optimal pterygopalatine fossa infiltration. ${ }^{22}$ This will ensure maximal vasospasm of the maxillary artery as well as a nerve block of the terminal branches of the maxillary nerve, with minimal risk to the orbital contents and infraorbital nerve.

Our experience with these two cases is that endoscopic SPA ligation is possible under local anesthesia and should be considered in patients with severe posterior epistaxis for whom a general anesthetic is unsuitable.

\section{Disclosures}

The authors report no conflicts of interest in this work.

\section{References}

1. O’Donnell M, Robertson G, McGarry GW. A New bipolar diathermy probe for the outpatient management of adult acute epistaxis. Clin Otolaryngol Allied Sci. 1999;4:534-541.

2. Schaitkin B, Strauss M, Hounck JR. Epistaxis: medical versus surgical therapy, a comparison of efficacy, complications and economic considerations. Laryngoscope. 1987;97:1392-1395.

3. Shaw CB, Wax MK, Wetmore SJ. Epistaxis: a comparison of treatment. Otolaryngol Head Neck Surg. 1993;109:60-65.

4. Asanau A, Timoshenko AP, Vercherin P, Martin C, Prades JM. Sphenopalatine and anterior ethmoidal artery ligation for severe epistaxis. Ann Otol Rhinol Laryngol. 2009;118(9):639-644.

5. Klotz DA, Winkle MR, Richmon J, Hengerer AS. Surgical management of posterior epistaxis: a changing paradigm. Laryngoscope. 2002;112:1577-1582.

6. Miller TR, Stevens ES, Orlandi RR. Economic analysis of the treatment of posterior epistaxis. Am J Rhinol. 2005;19:79-82.
7. Douglas R, Wormald PJ. Update on epistaxis. Curr Opin Otolaryngol Head Neck Surg. 2007;15:180-183.

8. Kumar S, Shetty A, Rockey J, Nilssen E. Contemporary surgical treatment of epistaxis. What is the evidence for sphenopalatine artery ligation? Clin Otol. 2003;28:360-363.

9. Prades J. Microcirurgia Endonasal de la Fosa Pterigomacilar y del Meato Medio. Barcelona: Salvat Editores 1980.

10. Budrovich R, Saetti R. Microscopic and endoscopic ligature of the sphenopalatine artery. Laryngoscope. 1992;102:1391-1394.

11. Feusi B, Holzman D, Steuer J. Posterior epistaxis: systematic review of the effectiveness of surgical therapies. Rhinology. 2005;43:300-304.

12. Lee HY, Kim HU, Kim SS, Son EJ, Kim JW, Cho NH, et al. Surgical anatomy of the sphenopalatine artery in lateral nasal wall. Laryngoscope. 2002;112:1813-1818.

13. Wareing MJ, Padgham ND. Osteologic classification of the sphenopalatine foramen. Laryngoscope. 1998;108:125-127.

14. Snyderman CH, Goldman SA, Carrau RL, Ferguson BJ, Grandis JR. Endoscopic sphenopalatine artery ligation is an effective method of treatment of posterior epistaxis. Am J Rhinol. 1999;13:137-140.

15. Abdelkader M, Leong SC, White PS. Endoscopic control of the sphenopalatine artery for epistaxis: long-term results. $J$ Laryngol Otol. 2007;121:759-762.

16. Averbukh SS, Brevda IS, Lubotsky DN, Semenova OS. The palatine access to the ganglion sphenopalatinum and to the second branch of the trifacial nerve. Ann Surg. 1935;101(3):819-826.

17. Wormald PJ, Athanasiadis T, Rees G, Robinson S. An evaluation of effect of pterygopalatine fossa injection with local anaesthetic and adrenalin in the control of nasal bleeding during endoscopic sinus surgery. Am J Rhinol. 2005;19:288-292.

18. Williams WT, Ghorayeb BY. Incisive canal and pterygopalatine fossa injection for hemostasis in septorhinoplasty. Laryngoscope. 1990;100:1245-1247.

19. Wormald PJ, Wee DTH, van Hasselt CA. Endoscopic ligation of the sphenopalatine artery for refractory posterior epistaxis. Am J Rhinol. 2000;14:261-264.

20. Mercuri LG. Intraoral second division nerve block. Oral Surg Oral Med Pathol. 1979;47:109-113.

21. Hwang JH, Liu CM, Liu TC, Hsu MC. Sphenopalatine ganglion block before removal of nasal packing. Laryngoscope. 2003;113(8): 1423-1424.

22. Douglas R, Wormald PJ. Pterygopalatine fossa infiltration through the greater palatine foramen: where to bend the needle. Laryngoscope. 2006;116:1255-1257.
Local and Regional Anesthesia

\section{Publish your work in this journal}

Local and Regional Anesthesia is an international, peer-reviewed, open access journal publishing on the development, pharmacology, delivery and targeting and clinical use of local and regional anesthetics and analgesics. The journal welcomes submitted papers covering original research, basic science, clinical studies, reviews \& evaluations,

\section{Dovepress}

guidelines, expert opinion and commentary, case reports and extended reports. The manuscript management system is completely online and includes a very quick and fair peer-review system, which is all easy to use. Visit http://www.dovepress.com/testimonials.php to read real quotes from published authors. 